An interesting fuct in the symptomatology of many cases of amenorrhoea from whatever cause, is the apparently vicarious character of leucorthca. I have several times been told that at regular intervals of time corresponding to what would be normal menstrual periods, there was an abundant leucorrhoeal discharge lasting severul days. I remember one case where this discharge was accompanied by pains which were-perfectly characteristic of those usually accompanying the menstrual period. The usual symptoms are those we observe in connection with the menopause, disturbances of the circulation, being the most prominent. Headache, flushing of the face, palpitation of the heart, weight and pressure in the pelvic region, and a tendency to grow stout are the most common.

The treatment of acquired amenorrhoa does not differ essentially from that of the primitive form. The same rules hold for treatment by general meas. ures alone, or by a combination of general and local. In the cases of amenorrhoer accompanied by atrophy, electricity would be the sheet anchor, and the faradic current which directly stimulates the muscular fibres of the uterus has been the most efficacious in my hands.

I have a very few times used a galvanic intra-uterine stem, but I never should resort to its use where it is possible to use the direct application of a strong current three or four times a week. The former is too mild and uncertain.

In the cases accompanied by obesity I should of course direct my efforts to reducing the fat as far as possible. I have never been able to carry out any elaborate course of trentment directed to this end, such as have been advocated in Germany by Oertel and Ebstein. These might prove more elficacious than my trials have been.

For the other varieties spoken of, general tonic treatment combined with locul in suitable cases, will usually result in cure.

The cessation of menstruation is not in all cases an evil. On the contrary there are cases where its absence must be looked upon as a conservative provision of nature to preveut unnecessary waste. In anæmic subjects, and in persons recovering from long and debilitating sickness, it would be unwise to institute active treatment for bringing this function into activity, unless the direct results of its cessation in the form of pain or disturbances of the circulation outweigh in importance the bad effects of the loss of blood.

Just how far this principle may be carried is a little doubtful. Gehrung, of St. Louis, has at two recent meetings of the American Gynecological Society advocated stopping menstruation by therapeutical measures, first in cases of menorrhagia and metrorrhagia, then in cases of scanty menstruation, and paradoxical as it muy seem in cases of amenorrhoea, that is, in such cases he does "his best to remove the disease or diseases upon which the amenorrhoea depends whether local or general, and as soon as the power to menstruate has returned, he uses the tampon to lessen or prevent the flow." His explanation is, that as temporary amenorrhosa occurs generally in anæmic or chlorotic individuals, it will easily be understood that the first step is to remove the cause, and the second to promote or render possible the convalescence.

These viows of Dr. Gehrung are extreme, but their explanation is found in the fact that he considers bloody menstruation a pathological process. Those of us who do not agree with this view, and I imagine that is the attitude of most of us, would hardly go so far as Dr. Gehrung, yet that the flow may be safely and wisely repressed or prevented in not a few cases, will, I think, be conceded by all. I have tried this method in some instances, using the tampon, and rest in bed if necessary, and have become satisfied that it may be of great value. While I have not had the brilliant results claimed for the method by Dr. Gehrung, yet I have, except in one case, had no unpleasant results, and have seen marked improvement follow it. In the case I speak of, the presence of the tampon at the time the catamenia were expected brought on such intense pelvic pain and headache that the tampon had to be removed, and menstruation allowed to begin, though after coutinuing for a day or two it was checked by a reapplication of the tampon with the happiest results.

'The treatment of this subject in this brief paper lias of necessity been such that its true character as a mere symptom of pathological conditions often obscure, has been thrown into the background. Progress in the true understanding of its real significance will alone enable us to be more successful in our thernpentical measures.

AMENORRHOEA : CLINICAL REPORT OF FOUR CASES SUCCESSFULLY TREATED BY GALVANISM.'

\author{
BY C. I. BTRONG, M.D.
}

Physician to Out-patients, Massachusetts Generch Hospital ; Assistant 'hysician to Out-patient, Massachusetts Genercl Mospital ; Assistant , vard Médical School.

Preliminary to the report of the cases presented this evening and to confine the discussion, I wish to state that the single subjective symptom of absence of menstrual flow, unaccompanied by physical change, has never seemed to me an indication for treatment. There is, however, one type of patients where various subjective symptoms, especially disturbances of the vasomotor system and other reflex phenomena are presented. Physical explanation, as by mal-development, displacement or recognizable abnormulity in the uterus itself or its adnexa is lacking. The patients are strong, healthy-looking women, not the viotims of anxmia or organic disease. When married they are sterile. The reflex nervous symptoms presented are akin to those accompanying the menopause. Cephalic pains, inaptitude for the usual employments, depression, perhaps, even tinged with melancholy, sleeplessness, and kindred disorders.

As regards the medical treatment of these cases, it may, regarding my own experience, be dismissed with a word - useless.

As regards the local treatment, whatever the means adopted, certain cases will bo found entirely obstinate, others amenable at one time may fail at another, while a not inconsiderable number will always be affected by the method suggested in this paper, a method devoid of danger even should its good results not be manifested. Until I employed the galvanic current I had met with no success in the treatment of these cases by any local measure. Since adopting this, I feel a reasonable degree of confidence in assuring patients of relief to their subjective symptoms, although I cannot always promise the certain induction of the catamenial flow.

1 Road before the Boston Society for Modical Observation, January, 1891. 
Case I. Mrs. X., twenty-nine, consulted me in the spring of 1887 . She was in all ways a perfect type of womanly development. 'There was nothing in her history pointing to uterine disturbance until complete cessation of menstruation three. months before her visit. Coincident with this she began to grow stout. The amenorrhœa did not disturb her, but distressing occipital and vertical headaches, sleeplessness and general nervousness ensued. General hygienic and therapeutic measures, for one month, gave no relief. Selectjug the day when the catamenia would naturally appear, I applied galvanism. Following the immediate brownish discharge there was a scanty menstrual flow. Biweekly sittings were continued through the month, aud the subsequent periods were normal in all respects, and continued so until October, 1890 (three and a half years). 'The headaches and nervous symptoms and the extra flesh all disappeared, not returning during this interval. When I saw her in October she was confined to her bed, suffering as before from reflex symptoms. Circumstances made it necessary that she should be attended for some time before it was possible to employ the former treatment. She improved but very little. Menstruation had been absent two months, but the exact date for its reappearance not being known, biweekly applications were made. Meustruation followed the third treatment, and has since continued, a single application being made on the date at which the flow could be expected. The other symptoms are also cured. ${ }^{2}$

Cask II. Mrs. T., twenty-six years of age, sterile, married five years. Large, finely furmed woman, accustomed to out-door life and much exercise. Consulted mo July 23, 1890. Last menstruation, March 15th. Never irregular before. Suspected pregnancy, and came to me for confirmation, although presenting none of the subjective symptoms of the condition. Nothing in any way abnormal about the pelvic organs could be detected. There were many reflex nervous symptoms, and the patient said she was growing stout rapidly. A single application was followed by menstruation, which continued regularly until November. 'Then there were two applications more required, and the flow has normally appeared twice since.

CAsw III. Mrs. J., twenty-eight years of age, married seven years. One child six years ago. Had always been irregular, the inter-menstrual period being five to seven weeks. 'This patient had very marked neurotic manifestations, almust "fixed ideas," a direct inheritunce, and the period of delay beyond the regular time was one of distressing exaggeration of these symp. toms, accompanied by great irritability.

March 20,1890, the date of the first visit, galvanism was applied. The flow, then three weeks overdue, appeared within twenty-four hours.

In April, following bi-weekly applications, menstruation was six days late.

May. Exactly twenty-eight days.

June. Applied once each week during the month; one week overdue.

July. Applied twice at the expected date; appeared in twenty-eight days.

August. Applied only once; two weeks overdue.

September. No galvanism, but plastic nperation performed; menstruation not recorded.

November. Applied once, just at the expected date; immediately appeared.

2 April 10, 1891. Mengtruation stlll regular.
Decembor. Applied twice, just at the expected date; menstruation three days late.

The full record of this case demonstrates certainly the action of the galvanic current in abridging by a considerable interval the usual delay in the appearance of the flow, and also it relieved to a very considerable degree (according to the patient's statement) the nervous symptoms attendant on this delay.

Cass IV. Miss D., twenty years old. Menstrual history one of great irregularity. 'The usual history was appearance of the flow twice in three months and then no more for four, six or even ten months.

March 14, 1889, date of first visit. Had not menstruated since July', 1888, eight months. Tho flow appeured at once, iormal in amount; reappeared again the next month; then was absent three months.

October 20, 1890. Has had no flow since July. Single application followed by scanty menstrual discharge, October $22 \mathrm{~d}$.

November 24th. Bi-weekly application; normal.

December 25th. Bi-woekly application; normal.

'liese cases represent a selected type of patieuts as described previously; and are not intended to include any and all cases of amenorrhoa to which I have applied galvanism with, as a rule, no inmediately successful results.

The method of application has been the introduction of an intra-uteriue electrode insulated to within an inch of its point which is made of platinum, a broad abdom. inal electrode of zinc covered with cotton. 'The current in my first case was not measured, but in all the later cases varied from fifteen to forty milliampères, being carefully measured. The positive pole was abdomiual and applied alternately over either ovarian region for fifteen minutes. Immediately, and for about twentyfour hours after the application, there was a brown discharge from the uterus. Thero was a marked difference in the patients with regard to the tolerance of the current. Occasionally very disagreemble crumpy pains were produced, but I have seen no other ill effect.

\section{RECENT PROGRESS IN SURGERY.1}

BY H. L. HURMLLL, M.D. AND H. W. OUBHINa, M.D.

CANCER OF THE BREAST.

The results of a radical operation (amputation of breast, dissection of the axilla, removal of the pectoral fascia) in thirty-nine cases, are reported by Bihler. ${ }^{18}$ The final results are interesting. Sixty-five per cent. were found to have died. In 12.5 per cent. the disease has recurred, but the patients still live. Twenty per cent. are cured, among whom three have lived inore than three years since the operation, and two have lived more than two years. 'The interval during which these operations wero performed is from 1886 to 1888 inclusive.

THF ETIOLOGY AND SURGICAI, TREATMENT OF SEPTIC PERITONITIS.

Reichel ${ }^{14}$ has contributed an interesting article on this subject. He thinks the absence of evidences of peritoneal inflammation at autopsies after laparotomies is not to be considered proof that death was not due

1 Continued from pago 360 .

1s Mlinolun. Dissertation, 1800 : Schmidt Jahrb., 1890, vol, 227, p. 261.

if Deutsche Zeitschr f.jChir., Bd. xxx, p. 1-84. 